\title{
A New Laccase of Lac 2 from the White Rot Fungus Cerrena unicolor 6884 and Lac 2-Mediated Degradation of Aflatoxin $B_{1}$
}

\author{
Zhimin Zhou ${ }^{1,2,3}$, Renkuan Li ${ }^{2,3}$, Tzi Bun Ng ${ }^{4}$, Yunyun Lai ${ }^{2,3}$, Jie Yang ${ }^{2,3}$ and Xiuyun Ye $\mathrm{e}^{1,2,3, *}$ \\ 1 College of Chemical Engineering, Fuzhou University, Fuzhou 350116, China; n180410016@fzu.edu.cn \\ 2 The Key Laboratory of Marine Enzyme Engineering of Fujian Province, Fuzhou University, \\ Fuzhou 350116, China; rkuanlee@fzu.edu.cn (R.L.); n180820012@fzu.edu.cn (Y.L.); T09136@fzu.edu.cn (J.Y.) \\ 3 National Engineering Laboratory for High-efficient Enzyme Expression, Fuzhou 350116, China \\ 4 School of Biomedical Sciences, Faculty of Medicine, The Chinese University of Hong Kong, Shatin, \\ New Territories, Hong Kong 999077, China; tzibunng@cuhk.edu.hk \\ * Correspondence: xiuyunye@fzu.edu.cn; Tel.: +86-591-2286-6376
}

Received: 22 June 2020; Accepted: 24 July 2020; Published: 27 July 2020

\begin{abstract}
Aflatoxin $\mathrm{B}_{1}\left(\mathrm{AFB}_{1}\right)$ is a known toxic human carcinogen and can be detoxified by laccases, which are multicopper oxidases that convert several environmental pollutants and toxins. In this study, a new laccase that could catalyze $\mathrm{AFB}_{1}$ degradation was purified and identified from the white-rot fungus Cerrena unicolor 6884. The laccase was purified using $\left(\mathrm{NH}_{4}\right)_{2} \mathrm{SO}_{4}$ precipitation and anion exchange chromatography, and then identified as Lac 2 through zymogram and UHPLC-MS/MS based on the Illumina transcriptome analysis of $C$. unicolor 6884 . Six putative laccase protein sequences were obtained via functional annotation. The lac 2 cDNA encoding a full-length protein of 512 amino acids was cloned and sequenced to expand the fungus laccase gene library for $\mathrm{AFB}_{1}$ detoxification. $\mathrm{AFB}_{1}$ degradation by Lac 2 was conducted in vitro at $\mathrm{pH} 7.0$ and $45^{\circ} \mathrm{C}$ for $24 \mathrm{~h}$. The half-life of $\mathrm{AFB}_{1}$ degradation catalyzed by Lac 2 was $5.16 \mathrm{~h}$. Acetosyringone (AS), Syrinagaldehyde (SA) and [2,2' -azino-bis-(3-ethylbenzothiazoline-6-sulfonic acid)] (ABTS) at $1 \mathrm{mM}$ concentration seemed to be similar mediators for strongly enhancing $\mathrm{AFB}_{1}$ degradation by Lac 2 . The product of $\mathrm{AFB}_{1}$ degradation catalyzed by Lac 2 was traced and identified to be Aflatoxin $Q_{1}\left(A_{F Q}\right)$ based on mass spectrometry data. These findings are promising for a possible application of Lac 2 as a new aflatoxin oxidase in degrading $\mathrm{AFB}_{1}$ present in food and feeds.
\end{abstract}

Keywords: laccase; Cerrena unicolor; aflatoxin $\mathrm{B}_{1}$; biodegradation; detoxification; product; transcriptome

Key Contribution: $A$ product identified to be $\mathrm{AFQ}_{1}$ was found from $\mathrm{Lac} 2$-mediated $\mathrm{AFB}_{1}$ degradation, indicating that $\mathrm{AFB}_{1}$ would be transformed during Lac 2-mediated $\mathrm{AFB}_{1}$ degradation.

\section{Introduction}

Aflatoxins (AFs), which are commonly produced by Aspergillus fungi such as Aspergillus flavus and Aspergillus parasiticus, are toxoids leading to fluorescence, human carcinogenicity and mutagenicity. The toxicity of AFs is related to the $\mathrm{C}_{8}-\mathrm{C}_{9}$ double bond of the difuran ring and the lactone ring within the coumarin ring $[1,2]$. Based on these data, $A F s$ can be structurally classified into two main groups: the cyclopentenone group (e.g., aflatoxin $B_{1}\left(A_{F B}\right.$, Figure 1), aflatoxin $M_{1}\left(A_{F M}\right)$, aflatoxin $Q_{1}\left(A F Q_{1}\right)$, and aflatoxicol), and the cyclo-lactone group (e.g., aflatoxin $\mathrm{G}_{1}\left(\mathrm{AFG}_{1}\right)$ and its derivatives); $\mathrm{AFB}_{1}$, among the various aflatoxins, is commonly considered to be the most carcinogenic, inhibiting the synthesis of DNA, RNA and proteins [3]. $\mathrm{AFB}_{1}$, a difuranocoumarin derivative, is not only a known 
human carcinogen, but it can also affect a wide range of commodities [4,5]. $\mathrm{AFB}_{1}$ and its metabolites are mainly distributed in corn, peanuts, rice, wheat, oil by-products, dairy products and condiments [6,7]. It is estimated that over 5 billion people worldwide are at risk of chronic exposure to AFs in food [4].

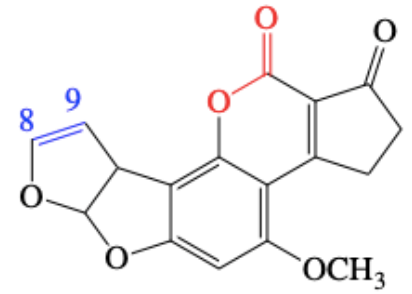

Figure 1. Chemical structure of aflatoxin $B_{1}\left(A_{F B}\right)$. The $C_{8}-C_{9}$ double bond is highlighted in blue, while the lactone bond is indicated in red.

Traditional methods of degradation of aflatoxin $B_{1}$, including physical [8], chemical [9], and microbial approaches [10], suffer from the drawbacks of being time consuming, the loss of nutrients, lowering of quality, increased cost, and formation of toxic residues or derivatives [11,12]. Enzymatic degradation of $\mathrm{AFB}_{1}$ is effective and environmentally friendly, especially in food and feed industries [13]. Enzymes reportedly employed for $\mathrm{AFB}_{1}$ degradation comprise mainly oxidoreductase, including aflatoxin oxidase enzyme (AFO) [14], peroxidase [15], $\mathrm{F}_{420} \mathrm{H}_{2}$-dependent reductases (FDR) [16], Mn peroxidase (MnP) [11,17], myxobacteria aflatoxin degrading enzyme (MADE) [18], bacillus aflatoxin-degrading enzyme (BADE) [19] and laccases [20-22]. The mechanisms of $\mathrm{AFB}_{1}$ degradation for these enzymes have been elucidated since they have different targets on $\mathrm{AFB}_{1}$ molecules and different active sites: AFO [23,24] and MnP [11] act on the bifuran ring; FDR catalyzes reduction of $\alpha, \beta$-unsaturated ester bond [16]; MADE acts on aromatic lactone and the methoxy group of the coumarin ring [18]. However, the mechanism of laccase-catalyzed $\mathrm{AFB}_{1}$ degradation has not been fully unraveled.

Laccases (EC 1.10.3.2) are copper-containing polyphenol oxidases which catalyze the oxidation of an array of aromatic substrates concomitantly with the reduction of molecular oxygen to water [25]. Laccases are produced by fungi for degrading lignin, humic compounds (phenols) and pollutant. However, few reports have focused on their effectiveness on toxins, like $\mathrm{AFB}_{1}$. Alberts et al. first found that the pure and recombinant laccases from Trametes versicolor could directly oxidize $\mathrm{AFB}_{1}$ with significant loss of mutagenicity, and its degradation products could not be detected after treatment using LCMS and HPLC [21]. In their hypothesis, the $\mathrm{C}_{8}-\mathrm{C}_{9}$ double bond in the furofuran ring might be responsible for the loss of the fluorescence and mutagenic properties of $\mathrm{AFB}_{1}$ with treatment of fungal laccases. Furthermore, the prooxidant properties and mutagenicity of the detoxification products obtained via laccase from T. versicolor have been studied by Hamed et al. [26]. Moreover, the interaction between AFs and laccases (T. versicolor [27] and Saccharomyces cerevisiae [28]), were studied by using 3D molecular techniques to gain an insight into the detailed mechanism of catalysis and decipher the reasons underlying the formation of degraded products.

Apart from T. versicolor laccases, Lac 2 from Pleurotus pulmonarius and Ery 4 from Pleurotus eryngii were also demonstrated by Loi et al. to degrade $\mathrm{AFB}_{1}$ via the mediation of natural phenolic compounds [22,29]. In their research, a laccase-mediator system (LMS) proved to enhance the degradation properties of laccases towards multiple mycotoxins. However, no degradation product of $\mathrm{AFB}_{1}$ catalyzed via LMS was identified. They hypothesized that the deeper modification of the coumarin-like core of the $\mathrm{AFB}_{1}$ would be responsible for the fluorescence quenching [22], which was different from the findings of Alberts et al. [21]. In addition, Wang et al. investigated whether CotA laccase from Bacillus subtilis (BsCotA) was capable of detoxifying $\mathrm{AFB}_{1}$ and zearalenone (ZEN) using structurally defined chemicals and complex natural mediators, and the degraded products of $\mathrm{AFB}_{1}$ using the LMS were detoxified [20]. In more recent studies, Guo et al. found that recombinant CotA laccase from Bacillus licheniformis transformed $\mathrm{AFB}_{1}$ to $\mathrm{AFQ}_{1}$ and epi- $\mathrm{AFQ}_{1}$, which did not suppress 
cell viability or induce apoptosis [30]. As summarized above, both molecular docking and product analysis were employed to ascertain the mechanism of $\mathrm{AFB}_{1}$ degradation. Nevertheless, neither the mechanism of fungal laccase-mediated $\mathrm{AFB}_{1}$ degradation, nor the detoxification products, have been fully elucidated. Therefore, the tasks of screening new fungal laccases and possible degradation products still pose great challenges and will open up new perspectives at molecular and product levels to clarify the mechanism.

Cerrena unicolor, known as a white-rot fungus of the Polyporaceae family, was previously reported to be an excellent producer of fungal laccase with an ability to degrade environmental pollutants [31]. Many studies have been undertaken on laccases from C. unicolor, including purification, characterization, cloning, heterologous expression, transcriptomic analysis and application [32-39]. Since laccases from T. versicolor and C. unicolor always share similar enzymatic properties [21], the study of $\mathrm{AFB}_{1}$ degradation by $C$. unicolor laccase would be a practical project based on those mentioned above. Our hypothesis is that $C$. unicolor laccase would be a workable and efficient candidate for $\mathrm{AFB}_{1}$ detoxification. In this study, we purified and identified a new laccase from $C$. unicolor and investigated its capability for $\mathrm{AFB}_{1}$ degradation. Our results showed that laccase from $C$. unicolor was a valuable enzyme in $\mathrm{AFB}_{1}$ degradation. Moreover, efforts were undertaken to identity the laccase- $\mathrm{AFB}_{1}$ degraded products to hypothesize on the active sites.

\section{Results}

\subsection{Species Identification}

A fragment of the Internal Transcribed Spacer (ITS) gene of the target fungal strain 6884 was amplified by PCR and sequenced, and 6884 was classified based on its sequence. A phylogeny tree (Figure S1) was constructed, indicating that 6884 was closest to Cerrena unicolor (GenBank accession No. FN907915.1), Cerrena unicolor strain 042 (EU661887.1), and three more Cerrena unicolor strains (MK937761.1, MH855029.1, MH979248.1), sharing 100\% sequence identity. The strain was named Cerrena unicolor 6884.

\subsection{Preparation and Purification}

After fermentation of C. unicolor 6884 for 14 days, laccase activity attained a maximum yield of $194 \mathrm{U} / \mathrm{mL}$ in the shake flask at $30^{\circ} \mathrm{C}$. On the fifth day of fermentation, C. unicolor 6884 produced laccase with an activity of $18.03 \mathrm{U} / \mathrm{mL}$, with which, $\mathrm{AFB}_{1}$ at the concentration of $5 \mu \mathrm{g} / \mathrm{mL}$ could almost be all degraded ( $98.56 \%$, Figure $2 \mathrm{~A}$ ). Meanwhile, $13.25 \%$ of $\mathrm{AFB}_{1}$ was degraded with laccase of fermentation broth possessing an activity of $9.54 \mathrm{U} / \mathrm{mL}$ on the second day. Considering the existence of other oxidases (e.g., peroxidase and $\mathrm{MnP}$, both of which have been shown to degrade $\mathrm{AFB}_{1}$ effectively $[11,15,17]$ ) besides laccase in the culture broth, the $\mathrm{AFB}_{1}$ degradation of the culture broth was significantly improved even though the laccase activity was still in its lag phase on the fifth day. Thus, it is difficult to prove a correlation between the laccase activity and $\mathrm{AFB}_{1}$ degradation with the culture broth. However, the purified laccase activity and $\mathrm{AFB}_{1}$ degradation were positively correlated as shown in Figure $\mathrm{S} 2$.

After 14 days of fermentation, laccase was purified from the fermentation supernatant by employing a protocol involving ammonium sulfate precipitation and ion exchange chromatography (DEAE) (Table 1). The specific activity of laccase was $68.07 \mathrm{U} / \mathrm{mg}$ in the fermentation medium. After ion exchange chromatography, the specific activity was increased to $1643.70 \mathrm{U} / \mathrm{mg}$, and the purification fold was 24.15. A purified protein band with a molecular weight of approximately $60 \mathrm{kDa}$ was detected in SDS-PAGE (Figure 2B, lane 1). Laccase activity was shown after native electrophoresis using guaiacol and 2,2' -azino-bis-(3-ethylbenzothiazoline-6-sulfonic acid) (ABTS) as substrates in lanes 2 and 3, respectively (Figure 2B). 
A

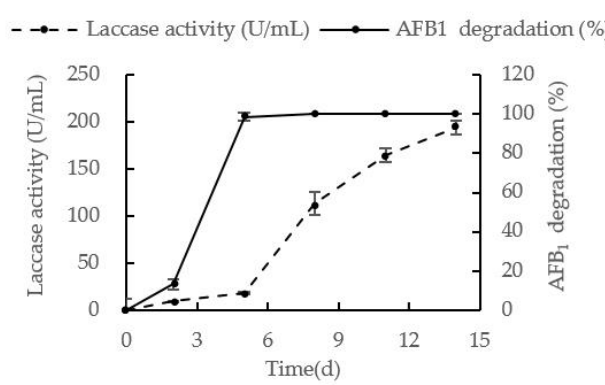

B

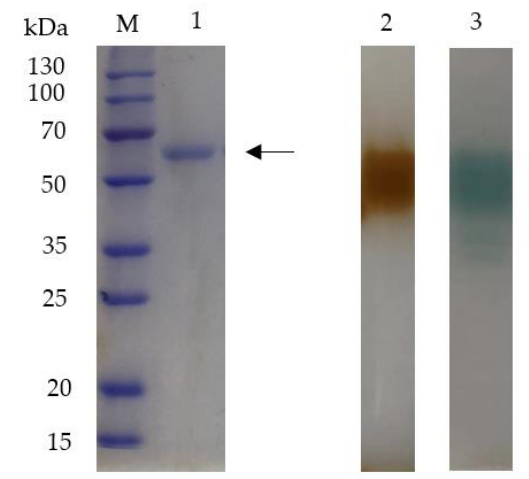

Figure 2. Preparation and zymogram of purified laccase from C. unicolor 6884. (A) Time course of laccase activity and $\mathrm{AFB}_{1}$ degradation mediated by the laccase. (B) Zymographic analysis of the purified laccase. Lane M: protein molecular weight marker by Takara; lane 1: purified laccase in SDS-PAGE; lane 2: purified laccase stained with guaiacol after electrophoresis; lane 3: purified laccase stained with 2,2' -azino-bis-(3-ethylbenzothiazoline-6-sulfonic acid) (ABTS) after electrophoresis. The samples applied to lanes 2 and 3 had not been heated before loading. The arrow indicates the purified laccase. In $\mathrm{A}$, the values represent means \pm standard errors $(n=3)$.

Table 1. Summary of laccase purification from culture filtrate of Cerrena unicolor 6884.

\begin{tabular}{cccccc}
\hline Purification Step & $\begin{array}{c}\text { Total } \\
\text { Activity (U) }\end{array}$ & $\begin{array}{c}\text { Total Protein } \\
(\mathbf{m g})\end{array}$ & $\begin{array}{c}\text { Specific Activity } \\
\text { (U/mg) }\end{array}$ & $\begin{array}{c}\text { Purification } \\
\text { Fold }\end{array}$ & $\begin{array}{c}\text { Recovery } \\
\text { (\%) }\end{array}$ \\
\hline Crude extract & $44,641.67$ & 655.86 & 68.07 & 1.00 & 100 \\
$\mathrm{NH}_{4}\left(\mathrm{SO}_{4}\right)_{2}$ & $33,653.33$ & 163.49 & 205.84 & 3.02 & 75.39 \\
$\begin{array}{c}\text { DEAE } \\
\text { cellulose }\end{array}$ & 6592.00 & 4.01 & 1643.70 & 24.15 & 14.77 \\
\hline
\end{tabular}

\subsection{Laccase Identification}

An mRNA-Seq approach was employed to gain insight into the laccase gene expression profile of C. unicolor 6884 during routine growth on PDA plates. A high-quality database containing a total of $39,419,310$ clean reads were obtained with a Q 30 Bases Ratio $95.33 \%$. The total number of reads was assembled to conduct the Transcript (numbers: 56591) and the Unigene (numbers: 13682, redundancy removal) of C. unicolor 6884. The whole sequences in Unigene were annotated against nine databases, including NR (NCBI non-redundant protein sequences, number of genes: 8732 , percentage: $63.82 \%$ ), NT (NCBI nucleotide sequences, 1410, 10.31\%), PFAM (Protein family, 4103, 29.99), KOG (euKaryotic Ortholog Groups, 4267, 31.19\%), Swiss-Prot (A manually annotated and reviewed protein sequence database, 5500, 40.2\%), KEGG (Kyoto Encyclopedia of Genes and Genomes, 1849, 13.51\%), CDD (Conserved Domain Database, 5060, 36.98\%), TrEMBL (A supplement of Swiss-Prot, 8692, 63.53\%) and GO (Gene Ontology, 6846, 50.05\%), to find genes encoding putative laccases. There were 23 genes in the Unigene functionally annotated to be putative laccases, and only six different sequences were obtained after blasting and assembling, named lac 1-lac 6 (Table S1). 
Based on the Illumina transcriptome analysis of $C$. unicolor 6884, six laccase cDNAs covering the four copper-binding motifs of fungal laccases (L 1-L 4) (Table S1) were annotated for the function of coding laccase. Information about the laccases is presented in Table S2. A database (DB) containing all six laccase protein sequences was customized for Proteome Discover software (version 2.2, 2018, Thermo Fisher Scientific, Germering, Germany).

Table 2 summarizes the identification of peptides that were digestion products from the single protein band in SDS-PAGE (Figure 2B, lane 1) with the highest score. As a result, 13 unique peptides were identified and assigned to Lac 2 from C. unicolor 6884 with $48 \%$ coverage. After purification and identification, laccase from C. unicolor 6884 was designated as Lac 2 . The deduced Lac 2 protein with 512 amino acids demonstrated the greatest resemblance (79\% identity) to laccase 2 precursor from Cerrena sp. HYB07 (Table S2). The 1536-bp cDNA of lac 2 was cloned and submitted to GenBank with the accession number MT232811.

Table 2. Analysis of the excised band using UHPLC-MS/MS in combination with Protein Discovery.

\begin{tabular}{|c|c|c|c|c|c|}
\hline $\begin{array}{c}\text { Assigned } \\
\text { Protein }\end{array}$ & Coverage $[\%]$ & Peptides & Sequence & Confidence & $\begin{array}{c}\text { Theo. MH+ } \\
\text { [Da] }\end{array}$ \\
\hline $\begin{array}{c}\text { Lac } 2 \text { from } \\
\text { Cerrena. } \\
\text { unicolor } \\
6884\end{array}$ & 48 & 13 & $\begin{array}{c}\text { VVELVIPPLAVGGPHPFHLHGHNFWVVR } \\
\text { TVGGPAQSPLNEADLRPLVPAPVPGNAVPGGADINHR } \\
\text { SQTGPADAELAVISVEHNKR } \\
\text { SQTGPADAELAVISVEHNK } \\
\text { SAGSDEYNFDDAILRDVVSIGAGTDEVTIR } \\
\text { SAGSDEYNFDDAILR } \\
\text { NASVEEPK } \\
\text { NAAILR } \\
\text { MLTPTSIHWHGFFQK } \\
\text { YSFVLNANQPDDNYWIR } \\
\text { MLTPTSIHWHGFYK } \\
\text { GAFVVYDPNDPHK } \\
\text { DVVSIGAGTDEVTIR } \\
\text { DLYDVDDESTVITLADWYHVLAQTVVGAATPDSTLINGLGR }\end{array}$ & High & $\begin{array}{c}3123.71556 \\
3653.91467 \\
2122.08872 \\
1965.98761 \\
3185.52331 \\
1672.74492 \\
873.43124 \\
657.40423 \\
1845.91049 \\
2114.99303 \\
1829.91557 \\
1458.70120 \\
1531.79623 \\
4404.18816\end{array}$ \\
\hline
\end{tabular}

\section{4. $A F B_{1}$ Degradation by Lac 2 from Cerrena Unicolor 6884}

Results of $\mathrm{AFB}_{1}$ degradation mediated by Lac 2 are shown in Figure 3. Fluorescence properties of the $\mathrm{AFB}_{1}$ molecule declined with the prolongation of the duration of incubation with Lac 2 as detected by a fluorescent detector (FLD) on HPLC (Agilent 1260 Infinity II Series, Agilent Technologies, Waldbronn, Germany).

The time-course analysis of $\mathrm{AFB}_{1}$ degradation is shown in Figure $3 \mathrm{~A}$. The percentage of $\mathrm{AFB}_{1}$ degradation was $50 \%$ after an incubation of $4 \mathrm{~h}$, increased steadily to $93 \%$ following an incubation of $24 \mathrm{~h}$, and then gradually ascended to $100 \%$ at the end of an incubation period of $36 \mathrm{~h}$. The half-life of $\mathrm{AFB}_{1}$ degradation catalyzed by Lac 2 was $5.16 \mathrm{~h}$ in this study (Figure 3B).

The optimal temperature for $\mathrm{AFB}_{1}$ degradation was investigated over a period of $8 \mathrm{~h}$ (Figure $3 \mathrm{C}$ ). The percentage of $\mathrm{AFB}_{1}$ degradation was lower than $45 \%$ when the reaction temperature was below $45^{\circ} \mathrm{C}$. However, the $\mathrm{AFB}_{1}$ degradation rate increased rapidly from $45 \%$ to $65 \%$ when the temperature rose from $40{ }^{\circ} \mathrm{C}$ to $45^{\circ} \mathrm{C}$. The percentage of $\mathrm{AFB}_{1}$ degradation was maintained at about $65 \%$ in the temperature range of $45^{\circ} \mathrm{C}$ to $55^{\circ} \mathrm{C}$. When the temperature was elevated to $60{ }^{\circ} \mathrm{C}$ and then to $65^{\circ} \mathrm{C}$, the percentage of $\mathrm{AFB}_{1}$ degradation fell to $55 \%$ and then to $41 \%$. Therefore, the optimal temperature for $\mathrm{AFB}_{1}$ degradation mediated by laccase from $\mathrm{C}$. unicolor 6884 lay between $45^{\circ} \mathrm{C}$ and $55^{\circ} \mathrm{C}$, as shown in Figure 3C. 


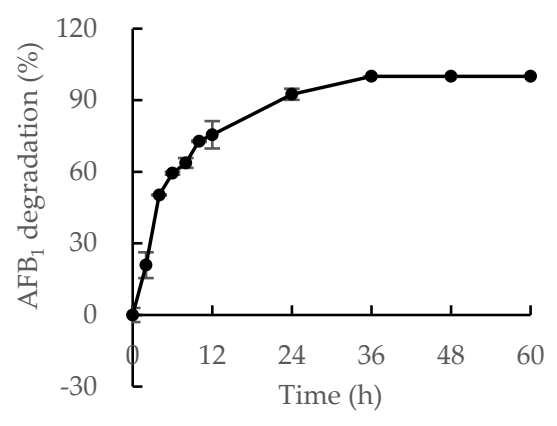

(A)

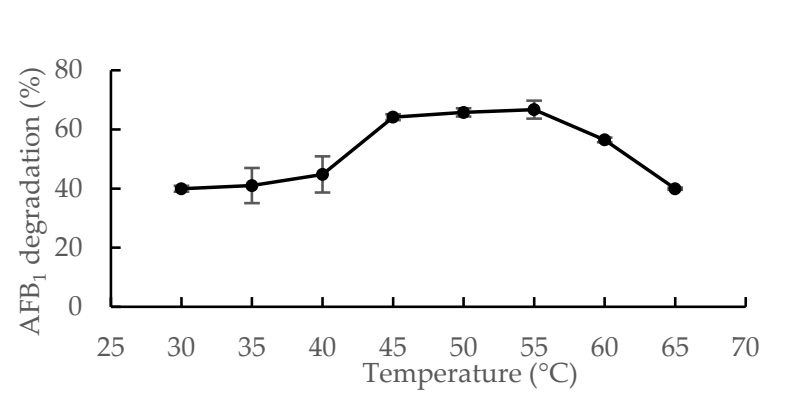

(C)

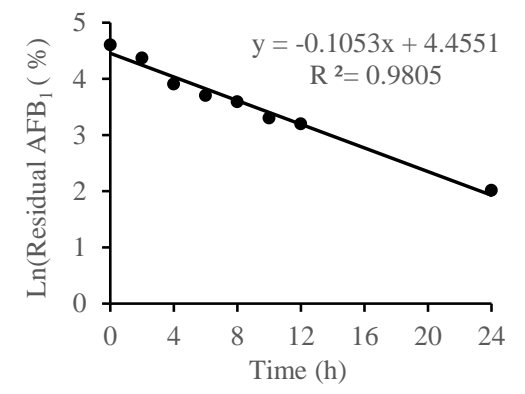

(B)

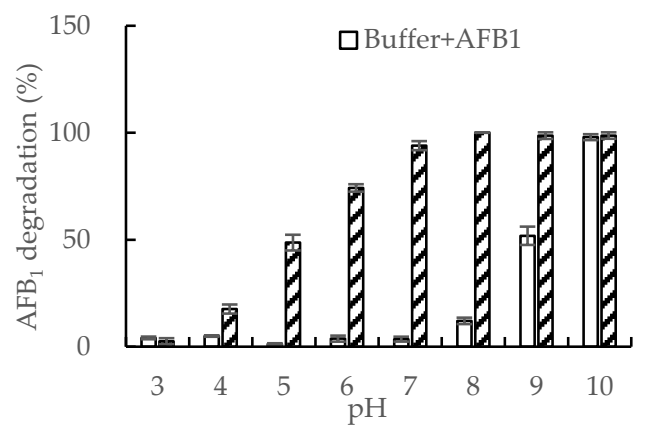

(D)

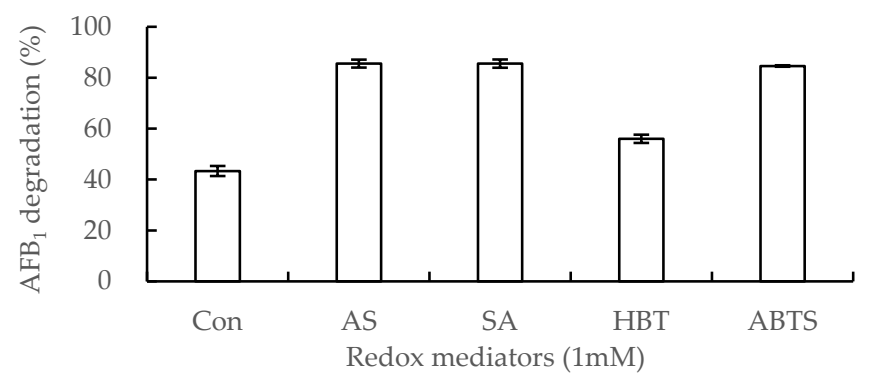

(E)

Figure 3. Cerrena unicolor $6884 \mathrm{Lac} 2$-mediated aflatoxin $\mathrm{B}_{1}\left(\mathrm{AFB}_{1}\right)$ degradation. $(\mathbf{A})$ and $(\mathbf{B})$ Time-course analysis of $\mathrm{AFB}_{1}$ degradation mediated by Lac 2 . $\mathrm{AFB}_{1}(5 \mu \mathrm{g} / \mathrm{mL})$ was incubated with Lac $2(50 \mathrm{U} / \mathrm{mL})$ in MilliQ water at $45^{\circ} \mathrm{C}$ over a period of $60 \mathrm{~h}$. Samples were periodically taken for HPLC. Effects of temperature (C), $\mathrm{pH}(\mathbf{D})$ and redox mediators $(\mathbf{E})$ on $\mathrm{AFB}_{1}$ degradation by Lac $2 . \mathrm{AFB}_{1}(5 \mu \mathrm{g} / \mathrm{mL})$ incubation with Lac $2(50 \mathrm{U} / \mathrm{mL})$ for $0 \mathrm{~h}$ were included as a treatment control. The residual $\mathrm{AFB}_{1}$ of all samples above was determined by a fluorescent detector (FLD) on HPLC (Agilent 1260 Infinity II Series, Agilent Technologies, Waldbronn, Germany). The values represent means \pm standard errors $(n=4)$.

$\mathrm{AFB}_{1}$ degradation was analyzed over a range $\mathrm{pH}$ values (3.0-10.0) by incubation of $\mathrm{AFB}_{1}$ with Lac 2 for $24 \mathrm{~h}$ (Figure 3D). When the $\mathrm{pH}$ was lower than 7.0 ( $\mathrm{pH} 3.0$ to 7.0), $\mathrm{AFB}_{1}$ degradation could not proceed without Lac 2 . The percentage of Lac 2-catalyzed $\mathrm{AFB}_{1}$ degradation was $94 \%$ when $\mathrm{pH}$ was 7.0. However, $\mathrm{AFB}_{1}$ was degradable in an alkaline buffer with a $\mathrm{pH}$ between 8.0 and 10.0. Thus, it is deduced that neutral $\mathrm{pH}$ was the optimal condition for $\mathrm{AFB}_{1}$ degradation by Lac 2 from C. unicolor 6884 (Figure 3D). The kinetic parameters, $K_{\mathrm{m}}, K_{\text {cat }}$ and $\mathrm{V}_{\max }$, of the Lac 2 towards $\mathrm{AFB}_{1}$ were $14.46 \mu \mathrm{M}$, $0.08 \mathrm{~s}^{-1}$ and $1.30 \mu \mathrm{g} \mathrm{min}^{-1} \mathrm{mg}^{-1}$, respectively.

Furthermore, different LMSs were studied for $\mathrm{AFB}_{1}$ degradation by Lac 2 over a period of $3 \mathrm{~h}$ (Figure $3 \mathrm{E}$ ). $\mathrm{AFB}_{1}$ degradation by Lac 2 was almost doubled ( $85 \%, 85 \%$ and $83 \%$ vs. $44 \%$, respectively) in the presence of $1 \mathrm{mM}$ AS, SA and ABTS. Syringyl-type phenols (AS and SA) and ABTS enhanced $\mathrm{AFB}_{1}$ degradation mediated by Lac 2 to similar extents, while hydoxybenzotriazole (HBT) promoted $\mathrm{AFB}_{1}$ degradation mediated by Lac 2 less effectively. 


\subsection{Analysis of Products of $A F B_{1}$ Degradation Catalyzed by Lac 2}

As shown in Figure $4 \mathrm{~A}$, the products of $\mathrm{AFB}_{1}$ formed as a result of catalysis by Lac 2 were analyzed by UHPLC (UltiMate 3000 series, Thermo Fisher Scientific, Germering, Germany) with a diode array detector (DAD) and mass detector (Q Exactive mass spectrometer, Thermo Fisher Scientific, Germering, Germany). With the prolongation of incubation time, the percentage of residual $\mathrm{AFB}_{1}$ gradually declined to zero. In the process of $\mathrm{AFB}_{1}$ degradation, a new fraction emerged in the chromatogram at an intermediate stage at about $3.57 \mathrm{~min}$ and subsequently vanished. The new fraction in the chromatogram exhibited the molecular formula $\mathrm{C}_{17} \mathrm{H}_{12} \mathrm{O}_{7}((\mathrm{M}+\mathrm{H})$, and demonstrated ${ }^{+}$ion peaks at $m / z 329.06458,\left(\mathrm{M}+\mathrm{NH}_{4}\right){ }^{+}$ion peaks at $m / z 346.09055$, and $(\mathrm{M}+\mathrm{Na}){ }^{+}$ion peaks at $m / z$ 351.04626) by UHPLC-MS/MS using Compound Discover software (version 3.0, 2018, Thermo Fisher Scientific, Germering, Germany). The mass spectrum of $\mathrm{AFB}_{1}$ and product are shown in Figures $4 \mathrm{~B}$ and $4 \mathrm{C}$, respectively.

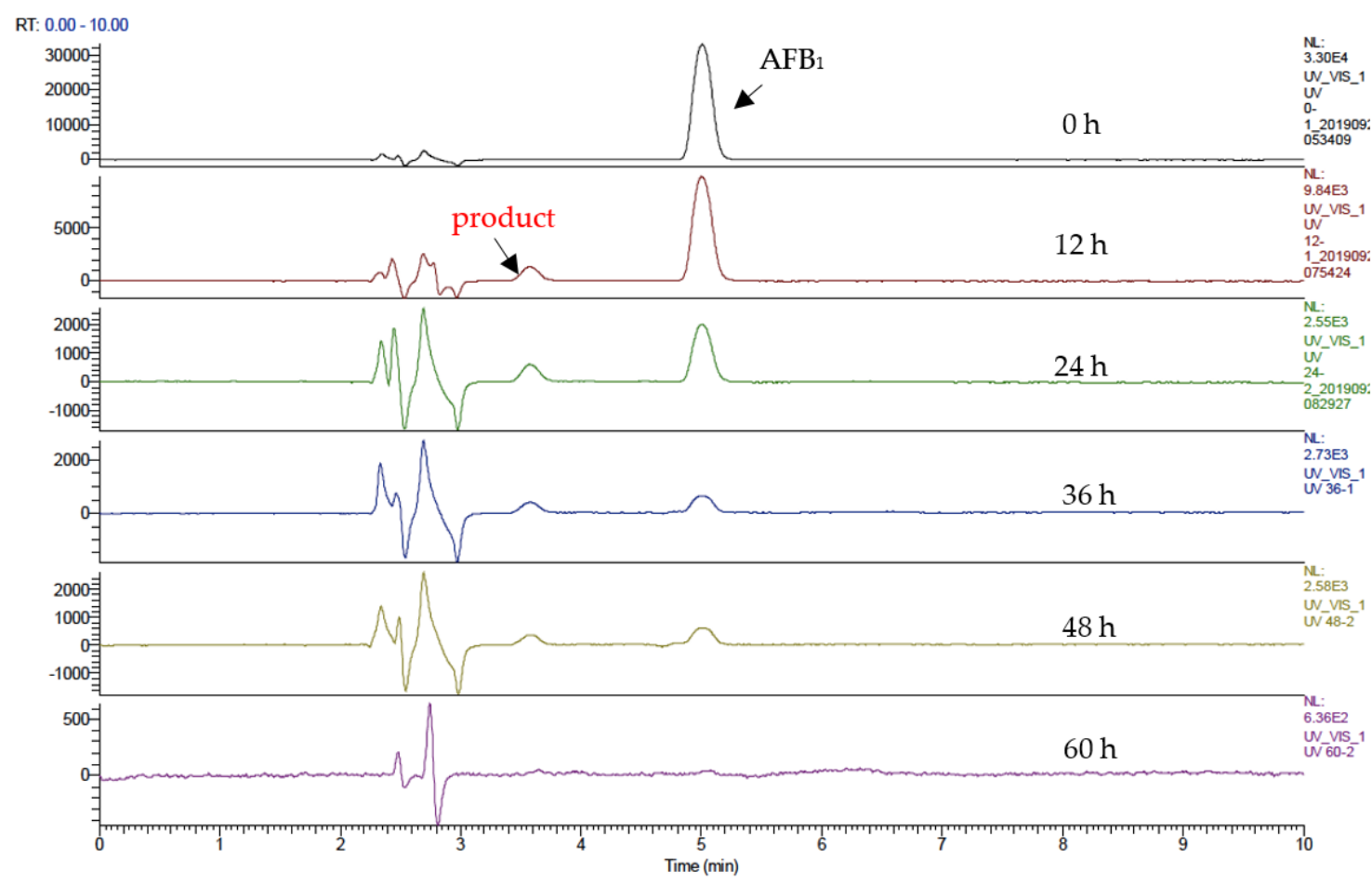

(A)

06-48-1 (F3) \#2629, RT=5.349 min, MS1, FTMS (+) $\mathrm{C} 17 \mathrm{H} 12 \mathrm{O} 6$ as $[\mathrm{M}+\mathrm{Na}]+1$

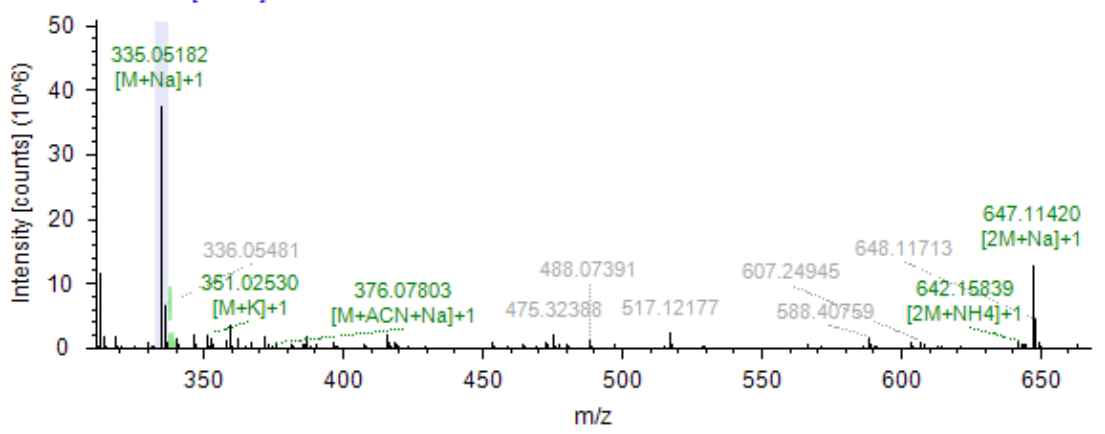

(B)

Figure 4. Cont. 


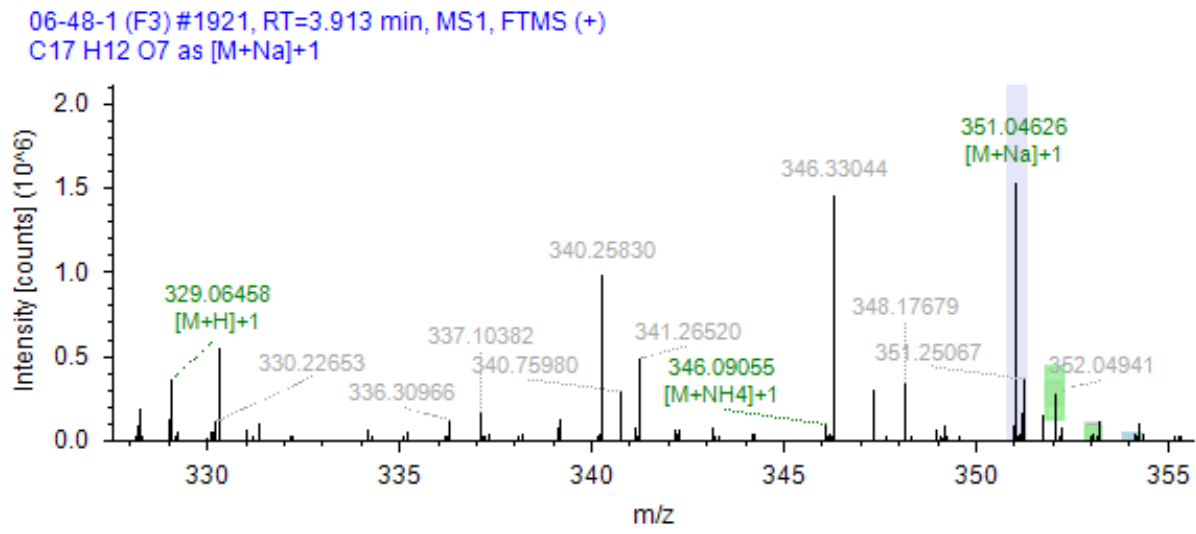

(C)

Figure 4. Mass spectral analysis of Lac 2-mediated aflatoxin $B_{1}$ degradation. NSI-MS experiments were performed using a Full MS in the positive ion mode. (A) Lac 2-mediated $\mathrm{AFB}_{1}$ degradation process over a period of $60 \mathrm{~h}$. Samples were periodically taken for UHPLC-MS/MS. AFB 1 and the product at the retention time of $5.349 \mathrm{~min}$ and $3.913 \mathrm{~min}$, respectively. (B) Mass spectrum of $\mathrm{AFB}_{1}\left(\mathrm{C}_{17} \mathrm{H}_{12} \mathrm{O}_{6}\right)$. (C) Mass spectrum of the product from Lac 2-mediated $A F B_{1}$ degradation $\left(\mathrm{C}_{17} \mathrm{H}_{12} \mathrm{O}_{7}\right)$.

\section{Discussion}

There were six genes encoding a hypothetical laccase in the genome of C. unicolor 6884 based on the results of Illumina transcriptome analysis. After purification and identification, the secreted laccase from C. unicolor 6884 was designated as Lac 2. The open reading frame (ORF) of lac 2 gene encoded a full-length protein of 512 amino acids with an estimated molecular mass of about $60 \mathrm{kDa}$, which is in the range of molecular masses of most fungal laccases with regular three domains $(50-70 \mathrm{kDa})$ [25]. Reports on laccases responsible for $\mathrm{AFB}_{1}$ degradation include the following: BsCotA from B. subtilis (Accession: AID81987.1) [20], laccase from T. versicolor (Accession: CAA77015.1 [21], PDB code: 1KYA [26,27]); Lac 2 from P. pulmonarius (Accession: AAX40733.1) [22]; and Ery4 from P. eryngii (Accession: CAO79915.1) [29]. Researchers have been trying to investigate the mechanism by employing both molecular techniques and direct analysis of degradation products. A homology model of $\mathrm{AFB}_{1}$ and laccase protein from T. versicolor has been analyzed by Dellafiora et al. [27]. The results showed that homology modeling was an effective analytical tool to assess the laccase- $\mathrm{AFB}_{1}$ interaction for explaining the mechanism of catalysis. It is necessary to acquire more laccase sequences to expand the library when studying the mechanism of laccase-catalyzed $\mathrm{AFB}_{1}$ degradation. In this study, we identified a new laccase from C. unicolor 6884, which demonstrated the ability to degrade $\mathrm{AFB}_{1}$.

After purification by $\left(\mathrm{NH}_{4}\right)_{2} \mathrm{SO}_{4}$ precipitation and anion exchange chromatography, the specific activity of purified Lac 2 was $1643.7 \mathrm{U} / \mathrm{mg}$ with ABTS as substrate, which is similar to those reported from Cerrena sp. WR1 (1013.5 U/mg) [40], C. unicolor BBP6 (1215.9 U/mg) [39] and Cerrena sp. HYB07 (1952.4 U/mg) [31]. Results of SDS-PAGE and zymogram suggested that Lac 2 is a monomeric protein (Figure 2B) resembling most fungal laccases from C. unicolor GSM-019 (63.2 kDa) [41] and Lepista nuda $(56 \mathrm{kDa})[42]$.

The plane-conjugated configuration of furofuran and cumarin rings is responsible for the AF fluorescence [43]. The fluorescence properties of the $\mathrm{AFB}_{1}$ molecule were determined with FLD on HPLC. Some laccases from white rot fungi are capable of degrading $\mathrm{AFB}_{1}$. Only $12.66 \%$ of $\mathrm{AFB}_{1}$ remained after catalysis by laccase from $T$. versicolor at $\mathrm{pH} 6.5$ for $72 \mathrm{~h}$ [21]. C. unicolor, a strain of white rot fungi we studied, is a representative wood-degrading basidiomycete used to produce laccase for degradation of environmental pollutants due to its high enzymatic activity toward a broad range of substrates. In vitro, Lac 2 from C. unicolor 6884 catalyzed degradation of $92.5 \% \mathrm{AFB}_{1}$ at $45^{\circ} \mathrm{C}$ for $24 \mathrm{~h}$, and then nearly $100 \%$ degradation after $36 \mathrm{~h}$ (Figure $3 \mathrm{~A}$ ). 
$\mathrm{AFB}_{1}$ is thermostable for its conjugated structure formed by the C8-C9 double bond, and it would not be dilapidated even at a high temperature of $160^{\circ} \mathrm{C}$ [44]. The enzyme-substrate reaction temperatures affect the enzyme activity and molecular motions. In our study, the optimal temperature range was between $45^{\circ} \mathrm{C}$ and $55^{\circ} \mathrm{C}$ (Figure 3C). The optimal temperature for laccase from T. versicolor was $35^{\circ} \mathrm{C}$ [26]. In the case of $\operatorname{Cot} A$ laccase from $B$. subtilis, the $\mathrm{AFB}_{1}$ degradation rate rose when temperature was raised from 20 to $50^{\circ} \mathrm{C}$, but the rate was not reduced when the temperature continued to increase to $80^{\circ} \mathrm{C}$ [20]. The optimal temperature for laccase-mediated $\mathrm{AFB}_{1}$ degradation depends on the source and species of origin of the laccase.

Exposure of $\mathrm{AFB}_{1}$ to alkaline conditions caused the formation of nonfluorescent derivatives [45]. In an alkaline buffer, the lactone bond in $\mathrm{AFB}_{1}$ will be opened when attacked by nucleophiles, especially $\mathrm{OH}_{-}$, and then the detectability of $\mathrm{AFB}_{1}$ toxicity will be shielded, but the nonfluorescent compounds formed are strongly toxic based on results of the chick embryo's test [12,46]. Our study showed similar results that buffers at $\mathrm{pH}$ 8.0, 9.0 and 10.0 were responsible for $\mathrm{AFB}_{1}$ degradation without laccase (Figure 3D). The extent of $\mathrm{AFB}_{1}$ degradation catalyzed by $\mathrm{Lac} 2$ at $\mathrm{pH} 7.0$ would be much greater than that in acidic buffers, which was similar to findings on CotA laccase from B. subtilis [20], but different from T. versicolor laccase with an optimal $\mathrm{pH}$ of 4.5. Furthermore, ABTS was studied as the substrate for the stability of Lac 2. After incubating Lac 2 at pH $6.0-9.0$ and $25^{\circ} \mathrm{C}$ for $24 \mathrm{~h}$ or $48 \mathrm{~h}$, over $75 \%$ or $65 \%$ of the original enzyme activity was retained, respectively (Figure S3), indicating that Lac 2 was relatively more stable at $\mathrm{pH}$ of 6.0 or above. Therefore, the neutral condition was suitable for $\mathrm{AFB}_{1}$ degradation catalyzed by Lac 2. Considering the stability of Lac 2 and the better effect of Lac 2 on $\mathrm{AFB}_{1}$ degradation at higher $\mathrm{pHs}$, the application of $\mathrm{AFB}_{1}$ degradation in the intestinal lumen of humans and non-ruminants presents an opportunity to investigate the potential applicability of feed enzymes in animal intestinal tracts. Therefore, in subsequent studies, Lac 2 will be immobilized to improve its resistance for further application.

LMS was efficient in improving degradation, as with purified laccases from the other white rot fungi. In this study, Lac 2 produced by C. unicolor 6884 degraded $\mathrm{AFB}_{1}$ (Figure 3E), which was similar to purified laccase from T. versicolor [21] and Lac 2 from P. pulmonarius [22]. As reported, Ery4-LMSs, $1 \mathrm{mM}$ AS, SA and ABTS were able to double the degradation percentage compared to Lac 2 alone $(85 \%$, $85 \%$ and $83 \%$ vs. $44 \%$, respectively), while HBT could improve degradation slightly. It took $13.86 \mathrm{~h}$ for the rate of $\mathrm{AFB}_{1}$ degradation catalyzed by Lac 2 to exceed $80 \%$ (Figure 3B), but only $3 \mathrm{~h}$ by addition of $1 \mathrm{mM}$ AS, SA or ABTS in the reaction mixture (Figure 3E). Mediators efficiently improved $\mathrm{AFB}_{1}$ degradation. Considering the reaction modes, the AS, SA (natural 2,6-dimethoxy-substituted phenols) and HBT (artificial compounds) share the Hydrogen Atom Transfer (HAT) mechanism, while ABTS (artificial compounds) follows the Electron Transfer (ET) mechanism [47]. Therefore, the potential use of Lac 2 in treatment of raw materials could be advantageous due to its redox mediators and LMS high efficiency.

Few reports are available on the catalytic mechanism deployed by laccase in degradation of $\mathrm{AFB}_{1}$ and the degradation products. Several chemical reactions including epoxidation, hydroxylation, dehydrogenation and reduction, etc., [22], have been speculated as the potential mechanism of $\mathrm{AFB}_{1}$ degradation, but most are merely hypotheses and have not been corroborated. It is necessary to develop methods for $\mathrm{AFB}_{1}$ degradation debris tracking. A recent study on $\mathrm{rCot} \mathrm{A}$ laccase from B. licheniformis revealed that $A F B_{1}$ could be oxidized to $A F Q_{1}$ and epi-AFQ ${ }_{1}$ [30]. However, studies on products derived from $\mathrm{AFB}_{1}$ formed by the catalytic action of a fungal laccase have not been described. We attempted to investigate the products of $\mathrm{AFB}_{1}$ degradation catalyzed by Lac 2 from C. unicolor 6884 in order to speculate a mechanism of action of fungal laccase.

In our study, a new conspicuous fraction eluted at about 3.57 $\mathrm{min}$ in the UHPLC chromatogram (Figure 4A) emerged at an intermediate stage but eventually became undetectable. The same results were observed when $\mathrm{AFG}_{1}$ was degraded with the catalytic assistance of Lac 2 (data not shown). Thus, it can be concluded that the cyclopentenone structure of $\mathrm{AFB}_{1}$ and the cyclo-lactone structure of $\mathrm{AFG}_{1}$ were not the target sites for $\mathrm{Lac} 2$. The new fraction had the molecular formula $\mathrm{C}_{17} \mathrm{H}_{12} \mathrm{O}_{7}$, which showed 
the molecular ion peak at $m / z 329.06458\left([\mathrm{M}+\mathrm{H}]^{+}\right), 346.09055\left(\left[\mathrm{M}+\mathrm{NH}_{4}\right]^{+}\right)$, and $351.04626([\mathrm{M}+\mathrm{Na}]$ $\left.{ }^{+}\right)$. Compared to $\mathrm{AFB}_{1}\left(\mathrm{C}_{17} \mathrm{H}_{12} \mathrm{O}_{6}\right)$, this formula shows addition of only one more oxygen, and it is considered to be an $\mathrm{AFB}_{1}$ metabolite. According to the results of UHPLC-MS/MS in Figure $4 \mathrm{~A}$ and Figure $\mathrm{S} 4$, the concentration of $\mathrm{AFB}_{1}$ gradually decreased to zero after incubation for $60 \mathrm{~h}$. In the whole process, the $\mathrm{AFB}_{1}$ metabolite increased in the first $4 \mathrm{~h}$, and then declined as $\mathrm{AFB}_{1}$ appeared. Therefore, part of $\mathrm{AFB}_{1}$ would be converted to the metabolite, which would be slowly degraded, such as that of $\mathrm{AFB}_{1}$ via Lac 2 during the following incubation.

To date, $\mathrm{AFB}_{1}, \mathrm{AFB}_{2}, \mathrm{AFM}_{1}, \mathrm{AFG}_{1}$ and $\mathrm{AFG}_{2}$, can be detoxified with laccases [22,28]. As we know, $\mathrm{AFB}_{1}$ can undergo in vivo hydroxylation to its derivatives, $\mathrm{AFM}_{1}, \mathrm{AFQ}_{1}$, or aflatoxicol [1]. In our hypothesis, the molecular formula of $\mathrm{C}_{17} \mathrm{H}_{12} \mathrm{O}_{7}$ for the $\mathrm{AFB}_{1}$ metabolite is an $\mathrm{AFB}_{1}$-like structure, probably $\mathrm{AFM}_{1}, \mathrm{AFQ}_{1}$, epi-AFQ $1, \mathrm{AFG}_{1}, \mathrm{AFG}_{2}$ or 8,9-AFB 1 epoxide, for these aflatoxins sharing the same $m / z$ and molecular formula. According to Loi et al. [48], comparing the MS/MS spectrum of the unknown $\mathrm{AFB}_{1}$ metabolite to equivalent spectra of all known $\mathrm{AFs}$ can give a clue about the identity of this metabolite. $\mathrm{AFQ}_{1}$ is a known $\mathrm{AFB}_{1}$ metabolite; however, it is not commercially available. The MS/MS spectra of $\mathrm{AFQ}_{1}$ was cited as a reference by Loi et al. [48], in which Dr. De Boevre generously provided the MS/MS spectra of $\mathrm{AFQ}_{1}$.

A comparison of the MS/MS spectra of $\mathrm{AFB}_{1}$ metabolite obtained in this study and equivalent spectra of $\mathrm{AFQ}_{1}$ [48] revealed a matching of most diagnostic ions, e.g., m/z 174.99153, 176.98946, $206.05647,283.05804,311.05396$ and 330.06827 (Figure S5). Based on these findings, the unknown AFB 1 metabolite hydroxylated by Lac 2 was extremely likely to be $\mathrm{AFQ}_{1}$.

\section{Conclusions}

In this study, the next-generation sequencing technology (NGS, Illumina transcriptome analysis) was deployed, and a high-quality Unigene was conducted and annotated against nine databases to a customized database for direct identification of a new laccase and cloning of its cDNA sequence. Six laccase cDNAs covering the four copper-binding motifs of fungal laccases were annotated for the function of coding laccase. A new Lac 2 that catalyzed $\mathrm{AFB}_{1}$ degradation was purified and identified from the white-rot fungus Cerrena unicolor 6884. The cDNA of lac 2 was cloned and submitted to GenBank. The extent of $\mathrm{AFB}_{1}$ degradation achieved at $\mathrm{pH} 7.0$ and $45^{\circ} \mathrm{C}$ and an incubation duration of $24 \mathrm{~h}$ with laccase as the enzyme was $94 \%$. The stability of Lac 2 , and the more extensive degradation of $\mathrm{AFB}_{1}$ at higher $\mathrm{pH}$ values suggest the potential applicability of feed enzymes in the animal intestinal tract. The freely additional of redox mediators and LMS high efficiency enhanced the potential applicability of Lac 2 in the treatment of raw materials. Additional studies on the immobilization of Lac 2 and Lac 2-mediated $\mathrm{AFB}_{1}$ degradation in the animal intestinal tract and raw food material processing are required.

The Lac 2-mediated $\mathrm{AFB}_{1}$ degradation product is surmised to be an $\mathrm{AFB}_{1}$-like structure through UHPLC-MS/MS. $\mathrm{AFB}_{1}$ may be converted to $\mathrm{AFB}_{1}$ metabolite partially with the catalytic assistance of Lac 2 , and all will then be transformed to degradation products with chemical properties that vastly differ from the AFs. Comparing the MS/MS spectra of $\mathrm{AFB}_{1}$ metabolite with equivalent spectra of $\mathrm{AFQ}_{1}$ led to the conclusion that the $\mathrm{AFB}_{1}$ metabolite was $\mathrm{AFQ}_{1}$. To our knowledge, this identification of the product represents the first characterization of the role of fungal laccase in $\mathrm{AFB}_{1}$ detoxification. The complete unraveling of the mechanism of $\mathrm{AFB}_{1}$ degradation induced by a laccase from white-rot fungus necessitates further investigations. Besides analysis of the degradation products, molecular technology will also be a tool for elucidating the reasons underlying the formation of degraded products.

\section{Materials and Methods}

\subsection{Organism, Chemicals and Other Materials}

The Cerrena unicolor 6884 strain was purchased from China Forestry Culture Collection Center (CFCC). pMD-18 T vector Kit was purchased from TAKARA (Dalian, Liaoning, China). E. coli Top10 and 
RevertAid First Strand cDNA Synthesis Kit was purchased from Thermo Scientific (Vilnius, Lithuania). Total RNA Extractor (Trizol) and BCA Protein Assay Kit were purchased from Sangon (Shanghai, China). Illumina transcriptome analysis and primer synthesis were performed by Sangon (Shanghai, China) and sequencing reactions were performed by Invitrogen (Guangzhou, Guangdong, China).

Chemicals for gel electrophoresis were supplied by Solarbio (Beijing, China) and TaKaRa (Dalian, Liaoning, China). Trypsin (proteomic grade), trizol, and SA (Syrinagaldehyde) were purchased from Thermo Fisher Scientific (Waltham, MA, USA). AFB 1 standards (purify $\geq 98 \%$ ) and ABTS (2-azino-di-[3-ethylbenzo-thiazolin-sulphonate]) were purchased from Sigma-Aldrich (St. Louis, MO, USA). AS (Acetosyringone) was purchased from Solarbio (Beijing, China). HBT (N Hydroxy benzorizole) was purchased from Aladdin (Shanghai, China). Acetonitrile (ACN), Methanol, formic acid (FA), and trifluoroacetic acid (TFA) used in mass spectrometry of HPLC grade were purchased from Merck (Darmstadt, Germany). Regenerable cellulose syringe filters, $0.22 \mu \mathrm{m}$ (size $13 \mathrm{~mm}$ ), were obtained from Jinteng (Tianjin, China). Other chemicals used were of analytical grade from Sinopharm (Shanghai, China).

\subsection{Phylogenetic Analysis}

Phylogeny of the strain was identified by using ITS sequencing. Genomic DNA was extracted with a DNA Quick Plant System (TIANGEN, Beijing, China), and universal primers ITS 1 and ITS 4 were used for amplification of ITS. The PCR product was sequenced. The ITS sequence has been submitted to GenBank with the accession number MT712199. The phylogenetic analysis (with 1000 bootstraps) was performed with MEGA version 7.0 by the neighbor-joining method. Other fungal ITS sequences used in this study were from GenBank.

\subsection{Illumina Transcriptome Analysis of Cerrena Unicolor 6884}

C. unicolor 6884 was routinely grown on PDA plates at $30^{\circ} \mathrm{C}$ for 4 days. The extraction of total RNA and the Illumina transcriptome analysis were both performed by Sangon. An mRNA-Seq approach was employed to gain insight into the laccase gene expression profile of C. unicolor 6884 during routine growth on PDA plates. The total number of reads was assembled with Trinity (Version 2.4.0) to conduct the Transcript and Unigene, and the Unigene of C. unicolor 6884 was submitted to NCBI with the SRA accession PRJNA644218. The whole sequences in Unigene were blasted against nine databases, including NR, NT, PFAM, KOG, Swiss-Prot, KEGG, CDD, TrEMBL and GO, to find genes encoding putative laccases. These putative laccase genes have been submitted to GeneBank with accession numbers MT720691, MT720692, MT720693, MT720694, MT720695 and MT720696, respectively.

\subsection{Production of Laccase}

The production of laccase was carried out as previously described in [38]. Briefly, C. unicolor 6884 was grown in $50 \mathrm{~mL}$ medium ( $2 \% \mathrm{v} / \mathrm{v}$ glycerol, $1.5 \% \mathrm{w} / \mathrm{v}$ peptone, $6 \mathrm{~g} \mathrm{KH}_{2} \mathrm{PO}_{4}, 4.14 \mathrm{~g} \mathrm{MgSO}_{4} \cdot 7 \mathrm{H}_{2} \mathrm{O}$, $0.3 \mathrm{~g} \mathrm{CaCl}_{2}, 0.18 \mathrm{~g} \mathrm{NaCl}, 0.0625 \mathrm{~g} \mathrm{CuSO}_{4} \cdot 5 \mathrm{H}_{2} \mathrm{O}, 0.018 \mathrm{~g} \mathrm{ZnSO}_{4} \cdot 7 \mathrm{H}_{2} \mathrm{O}, 0.015 \mathrm{~g} \mathrm{VB}_{1}, 1000 \mathrm{~mL} \mathrm{H}_{2} \mathrm{O}$ ) in $250 \mathrm{~mL}$ Erlenmeyer flasks at $30^{\circ} \mathrm{C}$ with shaking at $200 \mathrm{rpm}$. Samples were collected at regular time intervals $\left(0,2,5,8,11\right.$ and $14 \mathrm{~d}$, respectively) for enzyme activity assays and $\mathrm{AFB}_{1}$ degradation in vitro described below. The reaction mixture of $\mathrm{AFB}_{1}$ degradation contained cultured broth and $\mathrm{AFB}_{1}(5 \mu \mathrm{g} / \mathrm{mL})$ incubated at $45^{\circ} \mathrm{C}$ over a period of $60 \mathrm{~h}$. The samples were removed for HPLC analysis (Agilent 1260 Infinity II Series, Agilent Technologies, Waldbronn, Germany) as detailed underneath. The values represent means \pm standard errors $(n=3)$.

\subsection{Enzyme Assay}

Laccase activity was measured photometrically at $420 \mathrm{~nm}\left(\epsilon=36,000 \mathrm{M}^{-1} \cdot \mathrm{cm}^{-1}\right)$ according to the procedure described in [38]. The $2 \mathrm{~mL}$ reaction system contained $100 \mathrm{mM} \mathrm{pH} 3.0$ sodium acetate solution $(975 \mu \mathrm{L}), 0.5 \mathrm{mM}$ ABTS $(1000 \mu \mathrm{L})$ and an appropriate amount of enzyme solution 
$(25 \mu \mathrm{L})$. One unit was defined as the amount of enzyme which oxidized $1 \mu \mathrm{mol}$ of substrate per min. All measurements were carried out in triplicate.

\subsection{Purification of Laccase}

After cultivation for $14 \mathrm{~d}$, the fermentation culture was harvested, collected, centrifuged and fractionated by addition of $50 \%$ to $90 \%\left(\mathrm{NH}_{4}\right)_{2} \mathrm{SO}_{4}$. The precipitate was resuspended and desalted by dialysis against $20 \mathrm{mM}$ Tris- $\mathrm{HCl}$ buffer $(\mathrm{pH} 8.5)$ and applied to a HiTrap DEAE column $(15 \mathrm{~cm} \times$ $5 \mathrm{~cm}, 5 \mathrm{~mL}$, GE Healthcare Bio-Science Corp, Piscataway, USA) on an ÄKTA ${ }^{\mathrm{TM}}$ Purifier (GE Healthcare Bio-Science AB, Uppsala, Sweden). Adsorbed proteins were eluted with $0.2 \mathrm{M} \mathrm{NaCl}$ in $20 \mathrm{mM}$ Tris- $\mathrm{HCl}$ buffer ( $\mathrm{pH} 8.5$ ) and ultra-filtered with a membrane module (nominal MW cut-off 10-kDa) at 4000× $g$ for $20 \mathrm{~min}$. Electrophoretic analyses were performed according to Yang [31] with a little modification. Briefly, fractions with laccase activity were examined by SDS-PAGE on $12 \%$ gels stained with Coomassie brilliant blue R-250 (Sigma, St. Louis, MO, USA) and zymography (stained with $0.04 \mathrm{mM}$ guaiacol and 0.25 mM ABTS, respectively). Protein concentration was quantified by BCA Protein Assay Kit.

\subsection{Identification of Laccase by UHPLC-MS/MS}

The identification of laccase from C. unicolor 6884 by UHPLC-MS/MS was performed by cutting the laccase bands obtained by SDS-PAGE analysis. Protein digestion was accomplished according to the manufacturer's instructions with slight modifications, with trypsin incubation overnight at $37^{\circ} \mathrm{C}$ [22]. Digestion products were subsequently analyzed by UHPLC-MS/MS for peptide sequences on UltiMate 3000 RSLCnano/Q Exactive mass spectrometer (Thermo Fisher Scientific, Germering, Germany). NSI-MS experiments were performed using a Full MS/ddMS ${ }^{2}$ mass spectrometer system in the positive ion mode. Full MS was in the range $100-5000 \mathrm{~m} / \mathrm{z}$. Peptide separation was performed on an Acclaim PepMap ${ }^{\mathrm{TM}}$ RSLC-C18 analytical column $(75 \mu \mathrm{m} \times 15 \mathrm{~cm}, 2 \mu \mathrm{m}, 100 \AA$, nanoViper, Thermo Fisher Scientific, USA). The injection volume was $5 \mu \mathrm{L}$. The following linear elution gradient was used for the analytical separation: solvent B remained at $2 \%$ for $3 \mathrm{~min}$ at the beginning of the elution, it was then varied from $2 \%$ to $6 \%$ in $3 \mathrm{~min}$, from $6 \%$ to $28 \%$ in $45 \mathrm{~min}$, from $28 \%$ to $34 \%$ in $4 \mathrm{~min}$; then it was increased up to $95 \%$ in $2 \mathrm{~min}$ and this ratio was maintained constant for the following $13 \mathrm{~min}$. The percentage of B suddenly decreased at $2 \%$ and kept stable for $10 \mathrm{~min}$ for column reconditioning. The two reserves used were: $\mathrm{A}=2 \% \mathrm{ACN}+98 \% \mathrm{H}_{2} \mathrm{O}+0.04 \% \mathrm{FA}$ and $\mathrm{B}=80 \% \mathrm{ACN}$ $+20 \% \mathrm{H}_{2} \mathrm{O}+0.08 \% \mathrm{FA}$; flow rate was set at $300 \mu \mathrm{L} / \mathrm{min}$. The data were acquired and analyzed by Proteome Discover (version 2.2, 2017, Thermo Fisher Scientific, Germering, Germany).

\subsection{Cloning of the Laccase cDNA from Cerrena Unicolor 6884}

The strain C. unicolor 6884 was grown on PDA plates at $30^{\circ} \mathrm{C}$ for $4 \mathrm{~d}$. Total RNA was extracted with Total RNA Extractor (Trizol). The cDNA of C. unicolor 6884 was generated by RT-PCR from total RNA with RevertAid First Strand cDNA Synthesis Kit. Lac 2 was amplified by PCR with the primer pair (lac 2-F: 5'-ATGGGATTGAACTCGGCT-3'; lac 2-R: 5'-TTAAATAGCAGTTCCTTTCTTAGGC-3') using total cDNA of $C$. unicolor 6884 as the template. PCR products were inserted into the pMD18-T vector and transformed into E. coli top10 competent cells which were then cultured on an LB plate with $100 \mathrm{mg} / \mathrm{mL}$ ampicillin. Three positive clones of each fragment were sequenced. The cDNA sequence of lac 2 studied in this paper has been submitted to GenBank with the accession number MT232811.

The sequences of C. unicolor 6884 laccases were analyzed online BLAST (http://blast.ncbi.nlm.nih. gov/Blast.cgi). SignalP-5.0 was used for theoretical signal peptide determination (http://www.cbs.dtu. $\mathrm{dk} /$ services/SignalP/).

\subsection{In Vitro Degradation of $A F B_{1}$ with Lac 2}

For $\mathrm{AFB}_{1}$ degradation by Lac 2, a time-course analysis was carried out in the dark. The $200 \mu \mathrm{L}$ reaction mixture contained $30 \mu \mathrm{g} / \mathrm{mL}$ Lac $2(50 \mathrm{U} / \mathrm{mL})$ and $\mathrm{AFB}_{1}(5 \mu \mathrm{g} / \mathrm{mL})$ in MilliQ water at $45^{\circ} \mathrm{C}$ 
over a period of $60 \mathrm{~h}$. The samples were periodically (at $2 \mathrm{~h}, 4 \mathrm{~h}, 6 \mathrm{~h}, 8 \mathrm{~h}, 10 \mathrm{~h}, 12 \mathrm{~h}, 24 \mathrm{~h}, 36 \mathrm{~h}, 48 \mathrm{~h}$, and $60 \mathrm{~h}$ ) taken for HPLC analysis.

To investigate the effect of temperature on Lac 2-mediated $\mathrm{AFB}_{1}$ degradation, $\mathrm{AFB}_{1}(5 \mu \mathrm{g} / \mathrm{mL})$ was individually incubated with $\mathrm{Lac} 2(50 \mathrm{U} / \mathrm{mL})$ in $\mathrm{Na}_{2} \mathrm{HPO}_{4}$-citric acid buffer ( $\left.\mathrm{pH} 7.0\right)$ at various temperatures ranging from 30 to $65^{\circ} \mathrm{C}\left(30,35,40,45,50,55,60\right.$, and $\left.65^{\circ} \mathrm{C}\right)$ over a period of $8 \mathrm{~h}$.

To investigate the effect of $\mathrm{pH}$ on $\mathrm{AFB}_{1}$ degradation by $\mathrm{Lac} 2, \mathrm{AFB}_{1}(5 \mu \mathrm{g} / \mathrm{mL})$ was individually incubated with or without Lac $2(50 \mathrm{U} / \mathrm{mL})$ for $24 \mathrm{~h}$ at $45^{\circ} \mathrm{C}$ in buffers at different $\mathrm{pH}$ values, including $\mathrm{Na}_{2} \mathrm{HPO}_{4}$-citric acid buffers (pH 3.0-8.0), and $50 \mathrm{mM}$ glycine-NaOH buffers (pH 9.0-10.0), respectively.

To determine the kinetic parameters $\left(K_{\mathrm{m}}, K_{\text {cat }}\right.$ and $\left.\mathrm{V}_{\max }\right)$ for $\mathrm{AFB}_{1}$ degradation, the initial reaction rate was investigated by monitoring the removal of $\mathrm{AFB}_{1}$ (initial concentration from 1, 2, 3, 4, 5, 10, 20, and $25 \mu \mathrm{g} / \mathrm{mL}$ ) at $10 \mathrm{~min}$ intervals up to $50 \mathrm{~min}$ at $45^{\circ} \mathrm{C}$ and pH 7.0 with $30 \mu \mathrm{g} / \mathrm{mL}$ of Lac $2(50 \mathrm{U} / \mathrm{mL})$. The kinetic parameters were determined by nonlinear regression of Michaelis- Menten plots using the software GraphPad Prism 8.2.1 (San Diego, CA, USA). One unit of $\mathrm{AFB}_{1}$-degratation activity was defined as the quantity of laccase that detoxified $1 \mu \mathrm{g}$ of $\mathrm{AFB}_{1}$ per minute.

To investigate the effect of $\mathrm{LMS}$ on $\mathrm{AFB}_{1}$ degradation, ABTS, AS, SA or HBT was independently tested as redox mediators at $1 \mathrm{mM}$ with $\mathrm{Lac} 2(50 \mathrm{U} / \mathrm{mL})$ in $\mathrm{Na}_{2} \mathrm{HPO}_{4}$-citric acid buffer (pH 7.0) at $45^{\circ} \mathrm{C}$ for $3 \mathrm{~h}$, while controls did not have any mediator.

Incubation of $\mathrm{AFB}_{1}(5 \mu \mathrm{g} / \mathrm{mL})$ with Lac $2(50 \mathrm{U} / \mathrm{mL})$ for $0 \mathrm{~h}$ was included as a treatment control. The residual $\mathrm{AFB}_{1}$ in all aforementioned samples was determined by FLD on HPLC (Agilent 1260 Infinity II Series, Agilent Technologies, Waldbronn, Germany). The values represent means \pm standard errors $(n=4)$.

\subsection{0. $A F B_{1}$ Assay}

$\mathrm{AFB}_{1}$ was extracted from the samples with an equal volume of dichloromethane three times and evaporated under nitrogen gas at $50{ }^{\circ} \mathrm{C}$. The samples were dissolved in an equal volume of methanol and filtered (0.22 $\mu \mathrm{m}$, Jinteng, China).

HPLC analyses of the samples were performed on an Agilent 1260 Infinity II Series (Agilent Technologies, Waldbronn, Germany) using a Poroshell 120 EC-C18 column $(2.1 \times 50 \mathrm{~mm}, 1.9 \mu \mathrm{m}$, Agilent Technologies, Waldbronn, Germany). The mobile phase for elution was composed of methanol, aceto-nitrile and water $(1: 1: 2, v / v / v)$ at a flow rate of $0.1 \mathrm{~mL} / \mathrm{min}$ for $5 \mathrm{~min}$ at $40^{\circ} \mathrm{C}$. The sample injection volume was $2 \mu \mathrm{L}$. $\mathrm{AFB}_{1}$ was measured by a FLD Detector which was set at the wavelengths of $365 \mathrm{~nm}$ (excitation) and $450 \mathrm{~nm}$ (emission). The retention time of $\mathrm{AFB}_{1}$ was $2.5 \mathrm{~min}$.

The percentage of AFB1 degradation was calculated according to the following formula:

$$
\mathrm{D}(\%)=\left(\mathrm{A}_{0}-\mathrm{A}\right) / \mathrm{A}_{0} \times 100,
$$

where $\mathrm{D}$ was the degradation efficiency $(\%)$, and $\mathrm{A}_{0}$ and $\mathrm{A}$ represented the peak area of $\mathrm{AFB}_{1}$ before and after degradation, respectively.

\subsection{UPLC-MS/MS Analysis of $A F B_{1}$ Degradation Products}

The Lac 2-mediated $\mathrm{AFB}_{1}$ degradation products were detected by UHPLC-MS/MS. The degradation reaction was carried out in the dark at $45^{\circ} \mathrm{C}$ for $0 \mathrm{~h}, 2 \mathrm{~h}, 4 \mathrm{~h}, 6 \mathrm{~h}, 8 \mathrm{~h}, 10 \mathrm{~h}, 12 \mathrm{~h}, 24 \mathrm{~h}, 48 \mathrm{~h}$, and $60 \mathrm{~h}$. The Lac 2-mediated $\mathrm{AFB}_{1}$ degradation products were analyzed by UHPLC (Thermo Scientific UltiMate 3000 System, Thermo Fisher Scientific, Germering, Germany) coupled with a Q Exactive mass spectrometer (Thermo Fisher Scientific, Germering, Germany). NSI-MS experiments were performed in the positive ionization mode. The mobile phase, which consisted of water, methanol and acetonitrile $(1: 1: 2, v / v / v)$, was used for elution at a flow rate of $0.1 \mathrm{~mL} / \mathrm{min}$ for $10 \mathrm{~min}$ at $40^{\circ} \mathrm{C}$. An Hypersil Gold $\mathrm{C}_{18}$ column $(100 \times 2.1 \mathrm{~mm}, 1.9 \mu \mathrm{m}$, Thermo Fisher Scientific, Germering, Germany) was used for separation at a flow rate of $0.1 \mathrm{~mL} / \mathrm{min}$ for $10 \mathrm{~min}$ at $40^{\circ} \mathrm{C}$. The sample injection volume was $2 \mu \mathrm{L}$. $\mathrm{AFB}_{1}$ was measured by a DAD Detector at $365 \mathrm{~nm}$. The retention time of $\mathrm{AFB}_{1}$ was $5.0 \mathrm{~min}$. The $\mathrm{AFB}_{1}$ degradation products 
were identified and analyzed with the Compound Discover (version 3.0, 2018, Thermo Fisher Scientific, Germering, Germany).

Supplementary Materials: The following are available online at http://www.mdpi.com/2072-6651/12/8/476/s1, Table S1. Amino acid sequence alignment of the four conserved copper-binding sites of laccases from Cerrena unicolor 6884, Table S2. Information about laccases from Cerrena unicolor 6884, Figure S1. Phylogenetic relationships of Cerrena unicolor 6884 and related species based on ITS sequences. The numbers following the strains are accession numbers of ITS sequences. Bootstrap values at nodes are percentages of 1000 replicates. Scale bar indicates base substitutions/100 bases, Figure S2. The correclation between Lac 2 from Cerrena unicolor 6884 and aflatoxin $\mathrm{B} 1\left(\mathrm{AFB}_{1}\right)$ degradation. $\mathrm{AFB}_{1}(5 \mu \mathrm{g} / \mathrm{mL})$ was individually incubated with Lac 2 ranging from $0 \mathrm{U} / \mathrm{mL}$ to $50 \mathrm{U} / \mathrm{mL}$ in MilliQ water at $45^{\circ} \mathrm{C}$ over a period of $60 \mathrm{~h}$. Incubation for $0 \mathrm{~h}$ were included as treatment controls. The residual $\mathrm{AFB}_{1}$ of all samples above was determined by FLD on HPLC (Agilent 1260 Infinity II Series, Agilent Technologies, Waldbronn, Germany). The values represent means \pm standard errors $(n=4)$, Figure S3. Effects of $\mathrm{pH}$ on stability of Lac 2. $\mathrm{pH}$ stability was studied by incubating the purified enzyme at different $\mathrm{pH}$ values in $20 \mathrm{mM}$ Na2HPO4-citric acid buffers (pH 2.0-7.0), or $20 \mathrm{mM} \mathrm{Na2HPO} 4-\mathrm{NaOH}$ buffers (pH 9.0-10.0) at $25^{\circ} \mathrm{C}$ for 24 $\mathrm{h}$ or $48 \mathrm{~h}$, and the residual laccase activity was quantified at the optimum $\mathrm{pH}$ and temperature using ABTS as the substrate. The activity of the untreated enzyme was taken as $100 \%$. The values represent means \pm standard errors $(n=3)$, Figure S4. Biological degradation of aflatoxin $B_{1}\left(A_{F B}\right)$ by laccase Lac $2(50 U / m L)$ produced by Cerrena unicolor at $\mathrm{pH} 7.0$ and at $45^{\circ} \mathrm{C}$ over a period of $0,2,4,6,8,10,12,24,36,48$, and $60 \mathrm{~h}$. The residual $\mathrm{AFB}_{1}$ and intermediate product were determined by UHPLC (Thermo Scientific UltiMate 3000 System, Thermo Fisher Scientific, Germering, Germany). The values represent means \pm standard errors $(n=3)$, Figure S5. MS/MS spectra of unknown $\mathrm{AFB}_{1}$ metabolite.

Author Contributions: Data curation, Z.Z.; Formal analysis, Z.Z. and R.L.; Funding acquisition, J.Y. and X.Y.; Investigation, Z.Z. and Y.L.; Methodology, R.L. and J.Y.; Project administration, X.Y.; Resources, J.Y.; Supervision, R.L. and X.Y.; Writing-original draft, Z.Z.; Writing-review \& editing, R.L., T.B.N. and X.Y. All authors have read and agreed to the published version of the manuscript.

Funding: This research was funded by National Natural Science Foundation of China, grant number 31671795.

Conflicts of Interest: The authors declare no conflict of interest.

\section{Abbreviations}

$\begin{array}{ll}\text { ABTS } & {\left[2,2^{\prime} \text {-azino-bis-(3-ethylbenzothiazoline-6-sulfonic acid)] }\right.} \\ \text { ACN } & \text { Acetonitrile } \\ \text { AFB }_{1} & \text { aflatoxin } B_{1} \\ \text { AFG }_{1} & \text { aflatoxin } G_{1} \\ \text { AFM }_{1} & \text { aflatoxin } M_{1} \\ \text { AFQ }_{1} & \text { aflatoxin } Q_{1} \\ \text { AS } & \text { Acetosyringone } \\ \text { DAD } & \text { Diode array detector } \\ \text { DEAE } & \text { diethylamino ethyl } \\ \text { FLD } & \text { Fluorescent detector } \\ \text { HBT } & \text { Hydroxy benzotriazole } \\ \text { Lac } 2 & \text { laccase 2 } \\ \text { LMS } & \text { laccase mediator system } \\ \text { SA } & \text { Syrinagaldehyde }\end{array}$

\section{References}

1. Loi, M.; Fanelli, F.; Liuzzi, V.C.; Logrieco, A.; Mulè, G. Mycotoxin Biotransformation by Native and Commercial Enzymes: Present and Future Perspectives. Toxins 2017, 9, 111. [CrossRef] [PubMed]

2. Schroeder, T.; Zweifel, U.; Sagelsdorff, P.; Friederich, U.; Luethy, J.; Schlatter, C. Ammoniation of aflatoxincontaining corn: Distribution, in vivo covalent deoxyribonucleic acid binding, and mutagenicity of reaction products. J. Agric. Food Chem. 1985, 33, 311-316. [CrossRef]

3. Hussein, H. Toxicity, metabolism, and impact of mycotoxins on humans and animals. Toxicology 2001, 167, 101-134. [CrossRef]

4. Strosnider, H.; Azziz-Baumgartner, E.; Banziger, M.; Bhat, R.V.; Breiman, R.; Brune, M.-N.; Decock, K.; Dilley, A.; Groopman, J.; Hell, K.; et al. Workgroup Report: Public Health Strategies for Reducing Aflatoxin Exposure in Developing Countries. Environ. Health Perspect. 2006, 114, 1898-1903. [CrossRef] [PubMed] 
5. Mao, J.; He, B.; Zhang, L.; Li, P.; Zhang, Q.; Ding, X.; Zhang, W. A Structure Identification and Toxicity Assessment of the Degradation Products of Aflatoxin $B_{1}$ in Peanut Oil under UV Irradiation. Toxins 2016, 8, 332. [CrossRef]

6. Abrar, M.; Anjum, F.M.; Butt, M.S.; Pasha, I.; Randhawa, M.A.; Saeed, F.; Waqas, K. Aflatoxins: Biosynthesis, Occurrence, Toxicity, and Remedies. Crit. Rev. Food Sci. Nutr. 2013, 53, 862-874. [CrossRef]

7. Williams, J.H.; Phillips, T.D.; Jolly, P.E.; Stiles, J.K.; Jolly, C.M.; Aggarwal, D. Human aflatoxicosis in developing countries: A review of toxicology, exposure, potential health consequences, and interventions. Am. J. Clin. Nutr. 2004, 80, 1106-1122. [CrossRef]

8. Luo, X.; Wang, R.; Wang, L.; Li, Y.; Bian, Y.; Chen, Z. Effect of ozone treatment on aflatoxin $B_{1}$ and safety evaluation of ozonized corn. Food Control. 2014, 37, 171-176. [CrossRef]

9. Ji, N.; Diao, E.; Li, X.; Zhang, Z.; Dong, H. Detoxification and safety evaluation of aflatoxin $\mathrm{B}_{1}$ in peanut oil using alkali refining. J. Sci. Food Agric. 2016, 96, 4009-4014. [CrossRef]

10. Wang, Y.; Zhao, C.; Zhang, D.; Zhao, M.; Zheng, D.; Lyu, Y.; Cheng, W.; Guo, P.; Cui, Z. Effective degradation of aflatoxin $\mathrm{B}_{1}$ using a novel thermophilic microbial consortium TADC7. Bioresour. Technol. 2017, 224, 166-173. [CrossRef]

11. Wang, J.; Ogata, M.; Hirai, H.; Kawagishi, H. Detoxification of aflatoxin B1 by manganese peroxidase from the white-rot fungus Phanerochaete sordida YK-624. FEMS Microbiol. Lett. 2010, 314, 164-169. [CrossRef]

12. Jard, G.; Liboz, T.; Mathieu, F.; Guyonvarc'H, A.; Lebrihi, A. Review of mycotoxin reduction in food and feed: From prevention in the field to detoxification by adsorption or transformation. Food Addit. Contam. Part A 2011, 28, 1590-1609. [CrossRef] [PubMed]

13. Adebo, O.A.; Njobeh, P.B.; Gbashi, S.; Nwinyi, O.C.; Mavumengwana, V. Review on microbial degradation of aflatoxins. Crit. Rev. Food Sci. Nutr. 2015, 57, 3208-3217. [CrossRef] [PubMed]

14. Liu, D.; Yao, D.; Liang, R.; Ma, L.; Cheng, W.; Gu, L. Detoxfication of aflatoxin $B_{1}$ by Enzymes Isolated from Armillariella tabescens. Food Chem. Toxicol. 1998, 36, 563-574. [CrossRef]

15. Das, C.; Mishra, H. In vitro Degradation of Aflatoxin $B_{1}$ in Groundnut (Arachis hypogea) Meal by Horse Radish Peroxidase. LWT Food Sci. Technol. 2000, 33, 308-312. [CrossRef]

16. Taylor, M.C.; Jackson, C.J.; Tattersall, D.B.; French, N.; Peat, T.S.; Newman, J.; Briggs, L.J.; Lapalikar, G.V.; Campbell, P.M.; Scott, C.; et al. Identification and characterization of two families of $\mathrm{F}_{420} \mathrm{H}_{2}$-dependent reductases from Mycobacteria that catalyse aflatoxin degradation. Mol. Microbiol. 2010, 78, 561-575. [CrossRef]

17. Yehia, R.S. Aflatoxin detoxification by manganese peroxidase purified from Pleurotus ostreatus. Braz. J. Microbiol. 2014, 45, 127-133. [CrossRef]

18. Zhao, L.H.; Guan, S.; Gao, X.; Ma, Q.G.; Lei, Y.P.; Bai, X.M.; Ji, C. Preparation, purification and characteristics of an aflatoxin degradation enzyme from Myxococcus fulvus ANSM068. J. Appl. Microbiol. 2010, 110, 147-155. [CrossRef]

19. Xu, L.; Eisa Ahmed, M.F.; Sangare, L.; Liu, Y.; Selvaraj, J.N.; Xing, F.; Wang, Y.; Yang, H.; Liu, Y. Novel Aflatoxin-Degrading Enzyme from Bacillus shackletonii L7. Toxins 2017, 9, 36. [CrossRef]

20. Wang, X.; Bai, Y.; Huang, H.; Tu, T.; Wang, Y.; Wang, Y.; Luo, H.; Yao, B.; Su, X. Degradation of aflatoxin $B_{1}$ and zearalenone by bacterial and fungal laccases in presence of structurally defined chemicals and complex natural mediators. Toxins 2019, 11, 609. [CrossRef]

21. Alberts, J.; Gelderblom, W.; Botha, A.; van Zyl, W. Degradation of aflatoxin B 1 by fungal laccase enzymes. Int. J. Food Microbiol. 2009, 135, 47-52. [CrossRef]

22. Loi, M.; Fanelli, F.; Zucca, P.; Liuzzi, V.C.; Quintieri, L.; Cimmarusti, M.T.; Monaci, L.; Haidukowski, E.M.; Logrieco, A.F.; Sanjust, E.; et al. Aflatoxin B 1 and M1 Degradation by Lac2 from Pleurotus pulmonarius and Redox Mediators. Toxins 2016, 8, 245. [CrossRef]

23. Cao, H.; Liu, D.; Mo, X.; Xie, C.; Yao, D. A fungal enzyme with the ability of aflatoxin $\mathrm{B}_{1}$ conversion: Purification and ESI-MS/MS identification. Microbiol. Res. 2011, 166, 475-483. [CrossRef] [PubMed]

24. Wu, Y.-Z.; Lu, F.-P.; Jiang, H.-L.; Tan, C.-P.; Yao, D.-S.; Xie, C.-F.; Liu, D.-L.; Chu, M.-Q. The furofuran-ring selectivity, hydrogen peroxide-production and low $\mathrm{Km}$ value are the three elements for highly effective detoxification of aflatoxin oxidase. Food Chem. Toxicol. 2015, 76, 125-131. [CrossRef] [PubMed]

25. Giardina, P.; Faraco, V.; Pezzella, C.; Piscitelli, A.; Vanhulle, S.; Sannia, G. Laccases: A never-ending story. Cell. Mol. Life Sci. 2010, 67, 369-385. [CrossRef] [PubMed] 
26. Zeinvand-Lorestani, H.; Sabzevari, O.; Setayesh, N.; Amini, M.; Nili-Ahmadabadi, A.; Faramarzi, M.A. Comparative study of in vitro prooxidative properties and genotoxicity induced by aflatoxin $\mathrm{B}_{1}$ and its laccase-mediated detoxification products. Chemosphere 2015, 135, 1-6. [CrossRef] [PubMed]

27. Dellafiora, L.; Galaverna, G.; Reverberi, M.; Dall'Asta, C. Degradation of Aflatoxins by Means of Laccases from Trametes versicolor: An in Silico Insight. Toxins 2017, 9, 17. [CrossRef]

28. Liu, Y.; Mao, H.; Hu, C.; Tron, T.; Lin, J.; Wang, J.; Sun, B. Molecular docking studies and in vitro degradation of four aflatoxins $\left(\mathrm{AFB}_{1}, \mathrm{AFB}_{2}, \mathrm{AFG}_{1}\right.$, and $\left.\mathrm{AFG}_{2}\right)$ by a recombinant laccase from Saccharomyces cerevisiae. J. Food Sci. 2020, 85, 1353-1360. [CrossRef]

29. Loi, M.; Fanelli, F.; Cimmarusti, M.T.; Mirabelli, V.; Haidukowski, E.M.; Logrieco, A.F.; Caliandro, R.; Mulè, G. In vitro single and combined mycotoxins degradation by Ery4 laccase from Pleurotus eryngii and redox mediators. Food Control. 2018, 90, 401-406. [CrossRef]

30. Guo, Y.; Qin, X.; Tang, Y.; Ma, Q.; Zhang, J.; Zhao, L. CotA laccase, a novel aflatoxin oxidase from Bacillus licheniformis, transforms aflatoxin $\mathrm{B}_{1}$ to aflatoxin $\mathrm{Q}_{1}$ and epi-aflatoxin $\mathrm{Q}_{1}$. Food Chem. 2020, 325, 126877. [CrossRef]

31. Yang, J.; Lin, Q.; Ng, T.B.; Ye, X.; Lin, J. Purification and Characterization of a Novel Laccase from Cerrena sp. HYB07 with Dye Decolorizing Ability. PLoS ONE 2014, 9, e110834. [CrossRef] [PubMed]

32. Rogalski, J.; Janusz, G. Purification of Extracellular Laccase from Cerrena unicolor. Prep. Biochem. Biotechnol. 2010, 40, 242-255. [CrossRef] [PubMed]

33. Bekker, E.G.; Petrova, S.D.; Ermolova, O.V.; Elisashvili, V.I.; Sinitsyn, A.P. Extraction, purification and some properties of laccase from Cerrena unicolor. Biokhimiya 1990, 55, 2019-2024.

34. Michniewicz, A.; Ullrich, R.; Ledakowicz, S.; Hofrichter, M. The white-rot fungus Cerrena unicolor strain 137 produces two laccase isoforms with different physico-chemical and catalytic properties. Appl. Microbiol. Biotechnol. 2006, 69, 682-688. [CrossRef]

35. Janusz, G.; Mazur, A.; Checinska Sielaff, A.; Małek, W.; Rogalski, J.; Ohga, S. Cloning and characterization of a laccase gene from biotechnologically important basidiomycete Cerrena Unicolor. J. Fac. Agric. Kyushu Univ. 2012, 57, 41-49.

36. Kachlishvili, E.; Metreveli, E.; Elisashvili, V. Modulation of Cerrena unicolor laccase and manganese peroxidase production. SpringerPlus 2014, 3, 1-7. [CrossRef]

37. Pawlik, A.; Mazur, A.; Wielbo, J.; Koper, P.; Żebracki, K.; Kubik-Komar, A.; Janusz, G. RNA Sequencing Reveals Differential Gene Expression of Cerrena Unicolor in Response to Variable Lighting Conditions. Int. J. Mol. Sci. 2019, 20, 290. [CrossRef]

38. Yang, J.; Ng, T.B.; Lin, J.; Ye, X. A novel laccase from basidiomycete Cerrena sp.: Cloning, heterologous expression, and characterization. Int. J. Biol. Macromol. 2015, 77, 344-349. [CrossRef]

39. Zhang, J.; Sun, L.; Zhang, H.; Wang, S.; Zhang, X.; Geng, A. A novel homodimer laccase from Cerrena unicolor BBP6: Purification, characterization, and potential in dye decolorization and denim bleaching. PLoS ONE 2018, 13, e0202440. [CrossRef]

40. Chen, S.-C.; Wu, P.-H.; Su, Y.-C.; Wen, T.-N.; Wei, Y.-S.; Wang, N.-C.; Hsu, C.-A.; Wang, A.H.-J.; Shyur, L.-F. Biochemical characterization of a novel laccase from the basidiomycete fungus Cerrena sp. WR1. Protein Eng. Des. Sel. 2012, 25, 761-769. [CrossRef]

41. Wang, S.-S.; Ning, Y.-J.; Wang, S.-N.; Zhang, J.; Zhang, X.; Chen, Q.-J. Purification, characterization, and cloning of an extracellular laccase with potent dye decolorizing ability from white rot fungus Cerrena unicolor GSM-01. Int. J. Biol. Macromol. 2017, 95, 920-927. [CrossRef] [PubMed]

42. Zhu, M.; Zhang, G.; Meng, L.; Wang, H.; Gao, K.; Ng, T.B. Purification and Characterization of a White Laccase with Pronounced Dye Decolorizing Ability and HIV-1 Reverse Transcriptase Inhibitory Activity from Lepista nuda. Molecules 2016, 21, 415. [CrossRef] [PubMed]

43. Nicolás-Vázquez, M.I.; Méndez-Albores, A.; Moreno-Martínez, E.; Miranda, R.; Castro, M. Role of Lactone Ring in Structural, Electronic, and Reactivity Properties of Aflatoxin $\mathrm{B}_{1}$ : A Theoretical Study. Arch. Environ. Contam. Toxicol. 2010, 59, 393-406. [CrossRef] [PubMed]

44. Raters, M.; Matissek, R. Thermal stability of aflatoxin $B_{1}$ and ochratoxin A. Mycotoxin Res. 2008, 24, $130-134$. [CrossRef] [PubMed]

45. Doyle, M.P.; Marth, E.H. Aflatoxin is degraded at different temperatures and pH values by mycella of Aspergillus parasiticus. Eur. J. Appl. Microbiol. Biotechnol. 1978, 6, 95-100. [CrossRef] 
46. Kiermeier, F.; Ruffer, L. Veränderung von Aflatoxin $\mathrm{B}_{1}$ in Alkalischer Lösung. Z. Lebensm. Unters. Forch. 1974, 155, 129-141. [CrossRef]

47. Baiocco, P.; Barreca, A.M.; Fabbrini, M.; Galli, C.; Gentili, P. Promoting laccase activity towards non-phenolic substrates: A mechanistic investigation with some laccase-mediator systems. Org. Biomol. Chem. 2003, 1, 191-197. [CrossRef]

48. Loi, M.; Renaud, J.B.; Rosini, E.; Pollegioni, L.; Vignali, E.; Haidukowski, M.; Sumarah, M.W.; Logrieco, A.F.; Mulè, G. Enzymatic transformation of aflatoxin $B_{1}$ by Rh_DypB peroxidase and characterization of the reaction products. Chemosphere 2020, 250, 126296. [CrossRef]

(C) 2020 by the authors. Licensee MDPI, Basel, Switzerland. This article is an open access article distributed under the terms and conditions of the Creative Commons Attribution (CC BY) license (http://creativecommons.org/licenses/by/4.0/). 